\title{
PENENTUAN ARUS SPOT PLASMA DAN ARUS PLASMA LUCUTAN BUSUR PADA SISTEM SUMBER ELEKTRON KATODE PLASMA MENGGUNAKAN TEKNIK KOIL ROGOWSKI
}

\section{DETERMINATION OF PLASMA SPOT CURRENT AND ARC DISCHARGE PLASMA CURRENT ON THE SYSTEM OF PLASMA CATHODE ELECTRON SOURCES USING ROGOWSKI COIL TECHNIQUE}

\author{
Wirjoadi, Bambang Siswanto, Lely Susita R.M., Agus Purwadi, Sudjatmoko \\ Pusat Sains dan Teknologi Akselerator, BATAN \\ Jl. Babarsari Kotak Pos 6101 Ykbb, Yogyakarta 55281 \\ e-mail: wirjoadi@gmail.com
}

Diterima 19 Mei 2014, diterima dalam bentuk perbaikan 02 Juli 2015, disetujui 28 Juli 2015

\begin{abstract}
ABSTRAK
PENENTUAN ARUS SPOT PLASMA DAN ARUS PLASMA LUCUTAN BUSUR PADA SISTEM SUMBER ELEKTRON KATODE PLASMA MENGGUNAKAN TEKNIK KOIL ROGOWSKI. Telah dilakukan eksperimen uji fungsi sistem elektrode ignitor dan sistem elektrode generator plasma untuk menentukan arus spot plasma dan arus plasma lucutan busur dengan teknik koil Rogowski. Sistem elektrode ignitor yang mendapat catudaya dari sistem IDPS dapat menghasilkan arus spot plasma 11,68 ampere dengan lebar pulsa sekitar $33 \mu$ s; nilai tersebut lebih besar dari rancangan mungkin karena komponen elektronik yang digunakan pada sistem IDPS tidak sesuai dengan yang direncanakan. Untuk sistem elektrode generator plasma yang mendapatkan catudaya dari sistem ADPS mampu menghasilkan arus plasma lucutan busur sekitar 103,15 ampere dengan lebar pulsa sekitar $96 \mu$ s, dan nilai ini sesuai dengan yang direncanakan. Berdasarkan nilai arus plasma lucutan busur ini dapat ditentukan rapat elektron plasma, yaitu sekitar 10,12 × 1019 elektron $/ \mathrm{m}^{3}$ dan dengan nilai kerapatan elektron plasma ini, sistem elektrode ignitor dan generator plasma cukup baik jika digunakan sebagai sistem sumber elektron katode plasma.
\end{abstract}

Kata kunci: elektrode ignitor, generator plasma, spot plasma, plasma lucutan busur, kerapatan elektron plasma

\begin{abstract}
DETERMINATION OF PLASMA SPOT CURRENT AND ARC DISCHARGE PLASMA CURRENT ON THE SYSTEM OF PLASMA CATHODE ELECTRON SOURCES USING ROGOWSKI COIL TECHNIQUE. It has been done the function test experiments of ignitor electrode system and the plasma generator electrode system to determine the current spot plasma and arc discharge plasma current with Rogowski coil technique. Ignitor electrode system that gets power supply from IDPS system can generate the plasma spot current of 11.68 ampere to the pulse width of about $33 \mu \mathrm{s}$, this value is greater than the design probably because of electronic components used in the IDPS system was not as planned. For the plasma generator electrode system that gets power from ADPS system capable of producing an arc discharge plasma current around 103.15 amperes with a pulse width of about $96 \mu \mathrm{s}$, and this value as planned. Based on the value of the arc discharge plasma current can be determined plasma electron density, which is about $10.12 \times 10^{19}$ electrons $/ \mathrm{m}^{3}$, and with this electron density value, an ignitor electrode system and a plasma generator system is quite good if used as a plasma cathode electron source system.
\end{abstract}

Keywords: ignitor electrode, plasma generator, plasma spot, arc discharge plasma, plasma electron density

\section{PENDAHULUAN}

Dada saat ini sedang dikembangkan sebuah iradiator elektron berbasis SEKP (Sumber Elektron Katode Plasma) yang dapat menghasilkan berkas elektron dengan tampang-lintang besar. Jenis iradiator elektron tersebut sangat menarik untuk pemanfaatan yang melibatkan suatu bahan yang memiliki dimensi besar. Iradiator elektron 
J. Iptek Nuklir Ganendra

Ganendra Journal of Nuclear Science and Technology

Vol. 18 No. 2 Juli 2015: 87-93

banyak digunakan dalam teknologi radiasi, modifikasi permukaan bahan struktural, dan dalam sistem pemompaan media aktif laser gas, serta juga dimanfaatkan di bidang-bidang lainnya ${ }^{(1-4)}$.

Dalam sebuah iradiator elektron berbasis SEKP pada umumnya terdiri dari beberapa komponen utama, antara lain adalah sebuah bejana iradiator elektron; sebuah sistem SEKP yang terdiri dari dua buah sistem elektrode ignitor yang dilengkapi dengan catudaya lucutan pemicu IDPS (Ignitor Discharge Power Supply) dan sistem elektrode generator plasma yang disambungkan ke catudaya lucutan busur plasma ADPS (Arc Discharge Power Supply); sistem tegangan ekstraksi berkas elektron yang berfungsi mengekstraksi berkas elektron dari bejana generator plasma; dan sistem vakum yang menghampakan seluruh sistem hingga kehampaan sekitar $10^{-5}$ torr (4-5). Dalam sumber elektron katode plasma, berkas elektron yang memiliki tampang-lintang besar tersebut dihasilkan dengan ekstraksi elektron dari permukaan plasma volumetrik. Untuk menghasilkan berkas elektron dengan tampang-lintang besar, SEKP memiliki keuntungan jika dibandingkan dengan sistem katoda panas; terutama jauh lebih mudah untuk membentuk berkas elektron yang homogen daripada berkas elektron yang diemisikan oleh sistem katode panas ${ }^{(4)}$.

Dalam sistem elektrode ignitor terdiri dari katode dengan bahan magnesium yang dipisahkan dari anode stainless steel 304 menggunakan isolator silinder teflon. Jika pada saat anodenya dipasang tegangan pulsa cukup tinggi, maka akan timbul aliran muatan yang melewati permukaan isolator, kemudian setelah aliran muatan sampai di katode akan terjadi lucutan permukaan (surface discharge) yang disebut spot plasma. Lucutan permukaan ini sebagai pemicu terjadinya lucutan busur plasma dalam sistem elektroda generator plasma, kemudian dengan menggunakan sistem tegangan ekstraksi berkas elektron dapat diekstraksi ke luar dari permukaan plasma. Salah satu teknik untuk mendeteksi arus spot plasma dan arus lucutan busur plasma adalah teknik koil Rogowski.

Koil Rogowski adalah suatu kumparan yang dililitkan secara seragam pada kerangka ferit non magnetik, dan biasanya ada dua jenis penampang kumparan Rogowski yaitu persegi panjang atau bentuk lingkaran (6). Koil Rogowski telah lama digunakan dalam aplikasi daya listrik untuk mengukur frekuensi rendah sinusoidal dan arus transien ${ }^{(7)}$, pengukuran potensial magnetik dan untuk berbagai aplikasi sensor arus: relay pelindung (protective relaying), pengukuran arus tinggi, arus impuls (impuls current), dan arus transien dalam industri daya listrik, pengelasan tahanan dalam industri otomotif, fisika plasma dan lainnya ${ }^{\left({ }^{8}\right)}$. Beberapa keuntungan koil Rogowski antara lain adalah kesederhanaan dalam desain dan operasi, lebar-pita frekuensi yang luas dan tanggap dinamik yang baik dan tidak ada kejenuhan magnetik, biayanya murah dan presisi $(9,10,11)$.

Koil Rogowski beroperasi berdasarkan prinsip dasar hukum Faraday dimana kumparan ditempatkan di sekitar konduktor, dan medan magnet yang dihasilkan oleh pulsa arus menginduksikan tegangan dalam kumparan; tegangan keluaran ini sebanding dengan laju perubahan arus ${ }^{(12) .}$ Dalam makalah ini dibahas tentang analisis hasil eksperimen uji fungsi sistem elektrode ignitor dan sistem elektrode generator plasma untuk menentukan nilai arus spot plasma dan arus plasma lucutan busur menggunakan teknik koil Rogowski. Selanjutnya berdasarkan arus plasma lucutan busur ditentukan besarnya kerapatan elektron plasma yang dihasilkan dalam sistem elektrode generator plasma.

\section{METODOLOGI}

Diagram sistem elektrode dalam SEKP yang digunakan untuk uji fungsi sistem elektrode ignitor dan sistem elektrode generator plasma ditunjukkan pada Gambar 1. Koil Rogowski yang digunakan untuk mengukur arus spot plasma dipasang pada kabel keluaran IDPS (5) yang disambungkan pada anode sistem elektrode ignitor, dan koil Rogowski untuk menentukan arus plasma lucutan busur ditempatkan pada kabel keluaran ADPS (6) yang tersambung pada anode sistem elektrode generator plasma. Sebelum tegangan dari masing-masing catudaya IDPS dan ADPS dipasang, bejana generator plasma dihampakan menggunakan sistem vakum hingga mencapai derajad kehampaan sekitar 6 hingga $8 \times 10^{-4}$ Torr.

Berdasarkan Gambar 1, pada saat sistem IDPS sebagai sumber daya pemicu bekerja (5) maka generator akan mengirimkan pulsa tegangan tinggi melalui anode (2) dan selanjutnya melalui permukaan isolator teflon (8) sampai di katode magnesium (1) sehingga terbentuk lucutan permukaan atau spot plasma di permukaan katode (3); selanjutnya sistem ADPS sebagai sumber daya plasma lucutan busur (6) akan meneruskan pulsa spot plasma di katode (3) menjadi plasma di ruang anode, terbentuklah lucutan busur plasma (4). Sinyal spot plasma dan sinyal 
Penentuan Arus Spot Plasma dan Arus Plasma Lucutan Busur Pada Sistem Sumber Elektron Katode Plasma Menggunakan Teknik Koil Rogowski (Wirjoadi, Bambang Siswanto, Lely Susita R.M., Agus Purwadi, Sudjatmoko)

plasma lucutan busur yang dihasilkan oleh masing-masing koil Rogowski direkam menggunakan storage oscilloscope. Sistem IDPS memiliki spesifikasi pulsa tegangan keluaran $10 \mathrm{kV}$ dengan lebar pulsa sekitar $10 \mu \mathrm{s}$, dan sistem ADPS menghasilkan pulsa tegangan keluaran sekitar $1 \mathrm{kV}$ dengan lebar pulsa sekitar $100 \mu \mathrm{s}$.

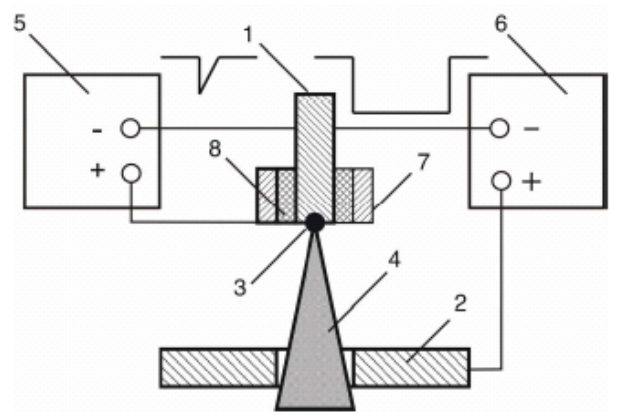

\section{Keterangan gambar:}

1. Katode

2. Anode

3. Spot plasma di permukaan katode

4. Plasma lucutan busur

5. Sumber daya pemicu lucutan (IDPS)

6. Sumber daya untuk plasma lucutan busur (ADPS)

7. Elektrode pemicu

8. Cincin isolator

Gambar 1. Diagram sistem elektrode untuk memicu lucutan busur plasma oleh lucutan permukaan pada katode.

Koil Rogowski memiliki prinsip kerja berdasarkan hukum Faraday; jika kumparan diletakkan di sekitar konduktor yang dialiri arus yang akan diukur, maka arus variabel ini akan menghasilkan medan magnet dan laju perubahan arus menginduksi tegangan dalam kumparan yang diberikan sebagai berikut $(6,12)$ :

$$
V_{k R}(t)=M \frac{d i(t)}{d t}=\frac{\mu_{0} n A}{2 \pi r} \frac{d i(t)}{d t}
$$

dengan $V_{k R}(t)$ adalah tegangan induksi dalam koil Rogowski oleh arus $i(t)$ yang mengalir dalam konduktor karena induktansi timbal-balik $M$ antara kumparan dan konduktor, $t$ adalah waktu, $\mu_{0}$ adalah tetapan permeabilitas $=4 \pi \times$ $10^{-7} \mathrm{H} / \mathrm{m}, n$ adalah jumlah lilitan koil Rogowski, $A$ adalah luas tampang-lintang koil dan $r$ adalah jari-jari koil.

Berdasarkan persamaan (1) dapat diketahui bahwa tegangan induksi sebanding dengan perubahan arus $\mathrm{d} i(\mathrm{t}) / \mathrm{d} t$, sehingga untuk menentukan besarnya arus $i(\mathrm{t})$ maka tegangan induksi atau tegangan keluaran koil Rogowski harus diintegralkan. Oleh karena itu, dalam eksperimen tegangan keluaran koil Rogowski digandengkan dengan rangkaian integrator $R C$, sehingga besarnya arus dapat ditentukan menurut persamaan

$$
i(t)=\frac{2 \pi r R C}{\mu_{\mathrm{t}} n A} V_{k R}(t)
$$

dimana $R$ adalah resistansi integrator pasif, $C$ adalah kapasitansi integrator, dan $\mu_{\mathrm{t}}$ adalah permeabilitas toroid. Spesifikasi teknik dari koil Rogowski untuk sistem IDPS dan sistem ADPS disajikan dalam Tabel 1.

Tabel 1. Spesifikasi koil Rogowski berinti ferit bentuk toroid untuk sistem IDPS dan ADPS.

\begin{tabular}{llccc}
\hline No. & Spesifikasi Koil Rogowski & Simbol & $\begin{array}{c}\text { Dimensi Rogowski Untuk } \\
\text { (IDPS) }\end{array}$ & $\begin{array}{c}\text { Dimensi Rogowski Untuk } \\
\text { (ADPS) }\end{array}$ \\
\hline 1 & Diameter luar & $\varnothing_{\text {kR }}=\varnothing_{\text {luar }}$ & $23 \mathrm{~mm}=23 \times 10^{-3}(\mathrm{~m})$ & $28 \mathrm{~mm}=28 \times 10^{-3}(\mathrm{~m})$ \\
\hline 2 & Diameter dalam & $\emptyset_{\text {dalam }}$ & $14 \mathrm{~mm}=14 \times 10^{-3}(\mathrm{~m})$ & $14,24 \mathrm{~mm}=14,24 \times 10^{-3}(\mathrm{~m})$ \\
\hline 3 & Diameter tengah & $\varnothing_{\text {tengah }}$ & $18,5 \mathrm{~mm}=18,5 \times 10^{-3}(\mathrm{~m})$ & $21,12 \mathrm{~mm}=21,12 \times 10^{-3}(\mathrm{~m})$ \\
\hline 4 & Tebal toroid & $t_{\mathrm{t}}$ & $10 \mathrm{~mm}=11 \times 10^{-3}(\mathrm{~m})$ & $11 \mathrm{~mm}=11 \times 10^{-3}(\mathrm{~m})$ \\
\hline 5 & Lebar toroid & $L_{\mathrm{t}}$ & $4,5 \mathrm{~mm}=4,5 \times 10^{-3}(\mathrm{~m})$ & $6,88 \mathrm{~mm}=6,88 \times 10^{-3}(\mathrm{~m})$ \\
\hline 6 & Jari-jari toroid & $r_{\text {torooid }}$ & $9,25 \mathrm{~mm}=9,25 \times 10^{-3}(\mathrm{~m})$ & $10,56 \mathrm{~mm}=10,56 \times 10^{-3}(\mathrm{~m})$ \\
\hline 7 & $\begin{array}{l}\text { Diameter kawat kumparan } \\
\text { untuk toroid }\end{array}$ & $\varnothing_{\text {kawat }}$ & $0,4 \mathrm{~mm}=0,4 \times 10^{-3}(\mathrm{~m})$ & $0,4 \mathrm{~mm}=0,4 \times 10^{-3}(\mathrm{~m})$ \\
\hline
\end{tabular}




\begin{tabular}{|c|c|c|c|c|}
\hline No. & Spesifikasi Koil Rogowski & Simbol & $\begin{array}{l}\text { Dimensi Rogowski Untuk } \\
\text { (IDPS) }\end{array}$ & $\begin{array}{l}\text { Dimensi Rogowski Untuk } \\
\text { (ADPS) }\end{array}$ \\
\hline 8 & $\begin{array}{l}\text { Jari-jari kawat kumparan } \\
\text { untuk toroid }\end{array}$ & $r_{\ell}$ & $0,2 \mathrm{~mm}=0,2 \times 10^{-3}(\mathrm{~m})$ & $0,2 \mathrm{~mm}=0,2 \times 10^{-3}(\mathrm{~m})$ \\
\hline 9 & $\begin{array}{l}\text { Jumlah kumparan untuk } \\
\text { toroid }\end{array}$ & $n$ & 76 & 80 \\
\hline 10. & $\begin{array}{l}\text { Luas tampang koil } \\
\text { Rogowski }\end{array}$ & $A_{\mathrm{kR}}$ & $45 \mathrm{~mm}^{2}=45 \times 10^{-6}\left(\mathrm{~m}^{2}\right)$ & $75,68 \mathrm{~mm}^{2}=75,68 \times 10^{-6}\left(\mathrm{~m}^{2}\right)$ \\
\hline 11. & Permeabilitas relatip & $\mu_{\mathrm{r}}$ & $81 \mathrm{H} / \mathrm{m}$ & $93 \mathrm{H} / \mathrm{m}$ \\
\hline 12. & Permeabilitas udara & $\mu 0$ & $12,56 \times 10^{-7} \mathrm{H} / \mathrm{m}$ & $4 \pi \times 10^{-7} \mathrm{H} / \mathrm{m}$ \\
\hline 13. & Permeabilitas toroid & $\mu_{\mathrm{t}}=\mu_{0} \cdot \mu_{\mathrm{r}}$ & $1017,36 \mathrm{H} / \mathrm{m}$ & $\left(4 \pi \times 10^{-7}\right) \times 93 \mathrm{H} / \mathrm{m}$ \\
\hline 14. & Induktansi toroid terukur & $L=\frac{\mu_{r} \mu_{0} N^{2} A}{\pi d}$ & $454 \mu \mathrm{H}=454 \times 10^{-6} \mathrm{H}$ & $852 \mu \mathrm{H}=852 \times 10^{-6} \mathrm{H}$ \\
\hline
\end{tabular}

15. Integrator pasif $R$ dan $C \quad R=100 \Omega$ dan $C=0,33 \mu \mathrm{F} \quad R=100 \Omega$ dan $C=2,2 \mu \mathrm{F}$

Berdasarkan persamaan (2) di atas karena masing-masing nilai tetapan dan besaran fisis dapat diketahui, maka nilai arus spot plasma dan arus plasma lucutan busur di dalam sistem SEKP dapat ditentukan. Karena 1 Coulomb untuk elektron adalah sebanyak 6,256 $\times 10^{18}$ elektron, jika ukuran elektrode generator plasma bentuk silinder jari-jari $r_{\mathrm{s}}$ dan panjang / diketahui, maka kerapatan elektron plasma $n_{\mathrm{e}}$ dalam bejana generator plasma dapat ditentukan menggunakan persamaan ${ }^{(13)}$

$$
n_{e}=\frac{\left(6,256 \times 10^{18}\right) Q}{\pi r_{g}^{2} l}
$$

dimana $Q=i_{\mid b} . \tau$ dengan $Q$ adalah muatan elektron, $i_{\mathrm{l}}$ adalah arus plasma lucutan busur dan $\tau$ adalah lebar pulsa tegangan sistem ADPS.

\section{HASIL DAN PEMBAHASAN}

Hasil uji fungsi sistem elektrode ignitor dan sistem elektrode generator plasma yang telah dilakukan masing-masing dapat digunakan untuk menentukan nilai arus spot plasma dan arus plasma lucutan busur dari sistem SEKP. Untuk mendeteksi arus spot plasma yang terjadi pada sistem elektrode ignitor (Gambar 2) digunakan teknik koil Rogowski, dan sinyal arus spot plasma yang terdeteksi pada storage oscilloscope ditampilkan pada Gambar 3.

Spot plasma atau lucutan permukaan pada permukaan katode ignitor terjadi karena isolator bentuk silinder dengan bahan teflon yang dipasang di antara katode dan anode sistem elektrode ignitor berperilaku sebagai kapasitor yang menerima muatan dari sistem IDPS melalui anode. Dalam selang waktu tertentu kapasitor teflon akan termuati penuh, dan oleh karena kapasitor teflon tersebut bertegangan $10 \mathrm{kV}$ dan menempel erat dengan katode yang dibuat dari bahan magnesium, maka kapasitor teflon akan melimpahkan seluruh energinya kepada katode dan oleh tegangan muatan yang ada di kapasitor teflon yang sangat besar terjadilah lucutan permukaan atau spot plasma pada permukaan katode. Untuk menimbulkan spot plasma pada permukaan katode ignitor, dibutuhkan tegangan sekitar $9-10 \mathrm{kV}$ pulsa dengan energi sekitar $100 \mathrm{~mJ}$ (5).

Berdasarkan Gambar 3 dari hasil eksperimen uji fungsi sistem elektrode ignitor diperoleh tegangan terukur $V_{\mathrm{kR}}=2,12$ volt dengan lebar pulsa $\tau=33 \mu \mathrm{s}$. Dengan memasukkan data dari Gambar 3 tersebut dan Tabel $1 \mathrm{ke}$ dalam persamaan (2) dapat ditentukan nilai arus spot plasma pada sistem elektrode ignitor yang dicatu oleh sistem IDPS. Berdasarkan Tabel 1, $r=$ jari-jari toroid $=9,25 \times 10^{-3} \mathrm{~m}, R=100 \mathrm{ohm}, C=0,33 \mu \mathrm{F}, \mu_{\mathrm{t}}=1.017,36 \mathrm{H} / \mathrm{m}, A=45$ 
Penentuan Arus Spot Plasma dan Arus Plasma Lucutan Busur Pada Sistem Sumber Elektron Katode Plasma Menggunakan Teknik Koil Rogowski (Wirjoadi, Bambang Siswanto, Lely Susita R.M., Agus Purwadi, Sudjatmoko)

$\times 10^{-6} \mathrm{~m}^{2}, n=76$ lilitan, dan tegangan $V_{\mathrm{kR}}=2,12$ volt, diperoleh arus spot plasma $i_{\mathrm{sp}}=11,68$ ampere dengan lebar pulsa $\tau=33 \mu \mathrm{s}$. Nilai arus spot plasma tersebut lebih besar dari nilai arus spot plasma yang direncanakan, yaitu sebesar 10 ampere dengan lebar pulsa sekitar $10 \mu \mathrm{s}$; hal ini terjadi mungkin disebabkan oleh nilai komponen elektronik sistem IDPS yang diperoleh dari pasaran dalam negeri tidak sesuai dengan yang direncanakan.

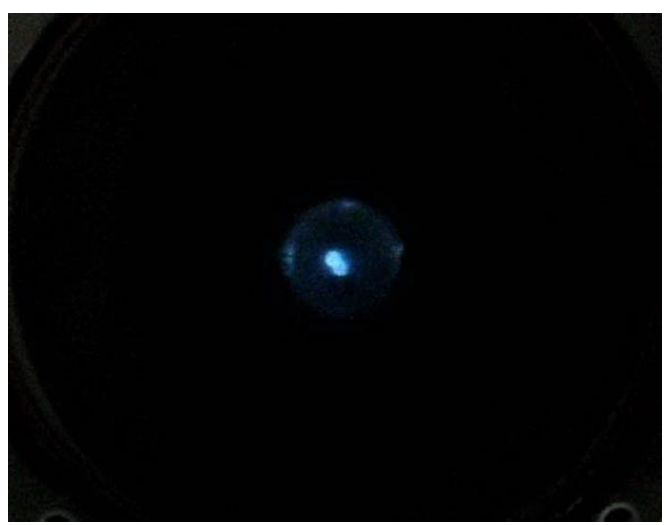

Gambar 2. Spot plasma yang terjadi pada permukaan katode sistem elektrode ignitor yang diamati dari salah satu ujung bejana generator plasma di depan sistem elektrode ignitor.

Setelah uji fungsi sistem elektrode ignitor, berikutnya dilakukan uji fungsi sistem elektrode generator plasma yang menghasilkan plasma lucutan busur. Lucutan busur ini dipicu oleh terjadinya spot plasma pada permukaan katode ignitor. Seperti pada penentuan arus spot plasma, arus plasma lucutan busur ditentukan menggunakan teknik koil Rogowski yang dilengkapi rangkaian integrator dan sebuah storage oscilloscope. Pada Gambar 4 ditampilkan foto plasma lucutan busur yang terjadi di dalam sistem elektrode generator plasma atau bejana generator plasma yang diamati pada salah satu ujung bejana generator plasma; sedangkan pada Gambar 5 ditampilkan sinyal plasma lucutan busur yang dideteksi menggunakan teknik koil Rogowski.

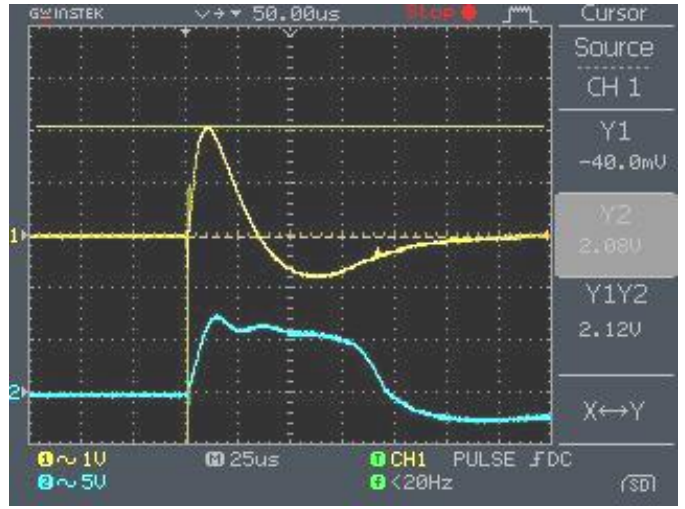

(a)

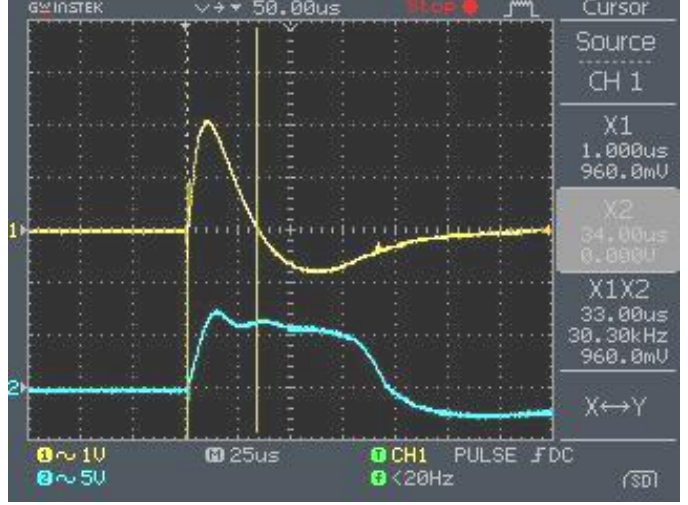

(b)

Gambar 3. Sinyal spot plasma pada permukaan katode yang dideteksi oleh koil Rogowski: (a) tegangan spot plasma terukur $V_{\mathrm{kR}}=2,12$ volt (gambar atas); (b) lebar pulsa spot plasma $\tau=33 \mu \mathrm{s}$ (gambar atas). 


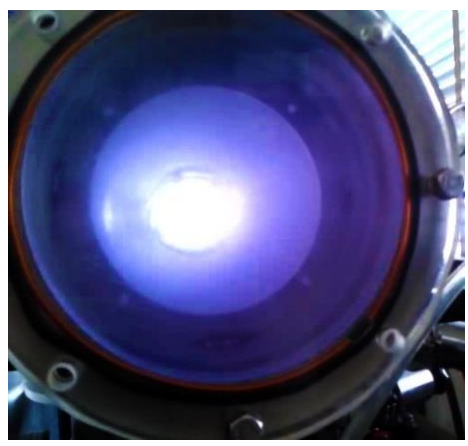

Gambar 4. Lucutan busur plasma yang terjadi di dalam sistem elektrode generator plasma dan diamati pada salah satu ujung bejana generator plasma.

Berdasarkan hasil eksperimen pengukuran arus plasma lucutan busur yang ditampilkan pada Gambar 5 , diperoleh tegangan pulsa $V_{\mathrm{lb}}=5,0$ volt dan lebar pulsa $\tau=96 \mu \mathrm{s}$. Untuk menentukan nilai arus plasma lucutan busur digunakan persamaan (2), dan dengan memasukkan data eksperimen pada Gambar 5, dan data-data pada Tabel 1: jari-jari toroid $r_{\text {toroid }}=10,56 \times 10^{-3} \mathrm{~m}, \mu \mathrm{t}=\left(4 \pi \times 10^{-7}\right) \times 93 \mathrm{H} / \mathrm{m}, n=80$ lilitan, $A=75,68 \times 10^{-6} \mathrm{~m}^{2}, R=100$ $\Omega, C=2,2 \times 10^{-6} \mathrm{~F}$ dan $V_{\mathrm{lb}}=5,0$ volt, diperoleh besarnya arus plasma lucutan busur $i_{\mathrm{lb}}=103,15$ ampere dengan lebar pulsa $\tau=96 \mu \mathrm{s}$. Hasil uji fungsi arus lucutan busur tersebut dapat dikatakan sama dengan yang diharapkan, yaitu arus plasma lucutan busur $i_{1 b}=100$ ampere dengan lebar pulsa $\tau$ sekitar $100 \mu$ s.

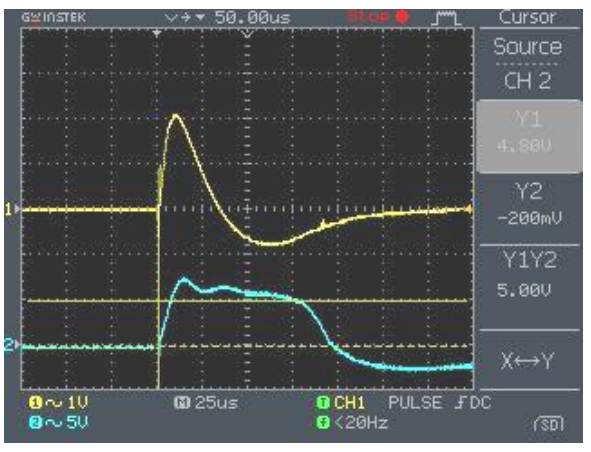

(a)

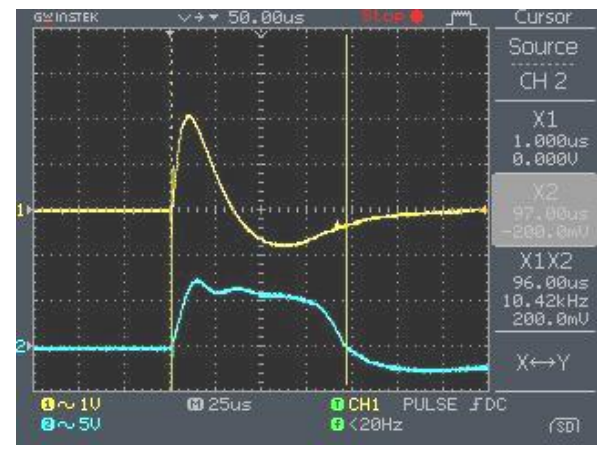

(b)

Gambar 5. Sinyal arus plasma lucutan busur pada elektrode generator plasma yang dideteksi oleh koil Rogowski: (a) tegangan lucutan busur plasma $V_{\mathfrak{l b}}=5,0$ volt (gambar bawah), dan (b) lebar pulsa $\tau=96 \mu \mathrm{s}$ (gambar bawah).

Plasma yang terbentuk di dalam sistem elektrode generator plasma berbentuk silinder dapat diketahui kerapatan elektron plasmanya jika nilai arus plasma lucutan busur dapat ditentukan. Berdasarkan persamaan (3) dapat ditentukan kerapatan elektron di dalam plasma yang terbentuk, dan dengan memasukkan nilai $Q=i_{\mathrm{lb}} \times \tau=$ $(103,15)\left(96 \times 10^{-6}\right)=9,902 \times 10^{-3} \mathrm{C}$, jari-jari silinder bejana generator plasma $r_{\mathrm{s}}=2,0 \times 10^{-2} \mathrm{~m}$, panjang silinder bejana generator plasma $I_{\mathrm{s}}=48,75 \times 10^{-2} \mathrm{~m}$, diperoleh nilai kerapatan elektron plasma dalam bejana generator plasma $n_{\mathrm{e}}=10,12 \times 10^{19}$ elektron $/ \mathrm{m}^{3}=10,12 \times 10^{13}$ elektron $/ \mathrm{cm}^{3}$. Menurut Oks ${ }^{(5)}$ untuk plasma dalam suatu sumber elektron, pada umumnya kerapatannya sekitar $10^{9}-10^{12} \mathrm{~cm}^{-3}$, karena sebagai persyaratan untuk terbentuknya berkas elektron yang baik. Sebagai perbandingan bahwa suatu gas pada suhu ruangan dan tekanan $1 \times 10^{-4}$ Torr menghasilkan kerapatan partikel sekitar 3,3 $\times 10^{12} \mathrm{~cm}^{-3}$. Jika dibandingkan dengan nilai kerapatan elektron plasma hasil analisis uji fungsi, diperoleh nilai kerapatan elektron plasma yang lebih besar, hal ini terjadi karena selama eksperimen uji fungsi tingkat kehampaan di dalam bejana generator plasma sekitar 6 hingga $8 \times$ $10^{-4}$ Torr. 
Penentuan Arus Spot Plasma dan Arus Plasma Lucutan Busur Pada Sistem Sumber Elektron Katode Plasma Menggunakan Teknik Koil Rogowski (Wirjoadi, Bambang Siswanto, Lely Susita R.M., Agus Purwadi, Sudjatmoko)

\section{KESIMPULAN}

Berdasarkan hasil dan pembahasan tersebut di atas dapat diambil beberapa kesimpulan sebagai berikut. Secara umum eksperimen uji fungsi sistem elektrode ignitor dan sistem elektrode generator plasma untuk menentukan arus spot plasma dan arus plasma lucutan busur dengan teknik koil Rogowski dapat dilakukan dengan baik sesuai dengan yang diharapkan. Sistem elektrode ignitor yang mendapat catudaya dari sistem IDPS dapat menghasilkan arus spot plasma 11,68 ampere dengan lebar pulsa sekitar $33 \mu \mathrm{s}$; nilai tersebut lebih besar dari rancangan karena mungkin komponen elektronik yang dipasang pada sistem IDPS adalah komponen lokal yang kurang sesuai dengan yang direncanakan. Untuk sistem elektrode generator plasma yang mendapatkan catudaya dari sistem ADPS dan dipicu oleh spot plasma mampu menghasilkan arus plasma lucutan busur sekitar 103,15 ampere dengan lebar pulsa sekitar $96 \mu \mathrm{s}$, dan nilai ini sesuai dengan yang direncanakan. Berdasarkan nilai arus plasma lucutan busur dapat ditentukan kerapatan elektron plasma, dan pada penelitian ini diperoleh sekitar 10,12 $\times 10^{19}$ elektron $/ \mathrm{m}^{3}$ yang cukup baik jika digunakan sebagai sistem sumber elektron katode plasma.

\section{UCAPAN TERIMA KASIH}

Dengan ini kami sebagai penulis makalah mengucapkan banyak terima kasih kepada Bapak Kepala PSTA-BATAN yang telah mengalokasikan dana penelitian dari DIPA-PSTA sehingga penelitian ini dapat dilaksanakan. Ucapan terima kasih juga kami sampaikan kepada Bapak Drs. Widdi Usada selaku narasumber, serta Sdr. Heri Sudarmanto, Sdr. Untung Margono dan Sdr. Ihwanul Aziz yang telah membantu teknis pelaksanaan uji fungsi untuk menentukan arus spot plasma pada sistem elektroda ignitor dan arus plasma lucutan busur pada elektroda generator plasma menggunakan teknik koil Rogowski, terutama pada saat melakukan konstruksi koil Rogowski, pelaksanaan eksperimen, pengambilan data dan foto hasil eksperimen. Semoga segala bantuan dan amal budi baik Bapak/Saudara mendapat balasan dari Allah SWT, Amiin.

\section{DAFTAR PUSTAKA}

1. J.Z. GLEIZER, V. VEKSELMAN, S. YATOM, J. FELSTEINER, and Y.E. KRASIK, Radiation Effects \& Defects in Solids, iFirst, (2011) 1 - 10

2. Y.E. KRASIK, D. YARMOLICH, J.Z. GLEIZER, V. VEKSELMAN, Y. HADAS, V.T. GUROVICH, and J. FELSTEINER, Physics of Plasmas 16, 057103 (2009) 057103-1 - 057103-11

3. J.Z. GLEIZER, Y. HADAS, V.T. GUROVICH, J. FELSTEINER, and Y.E. KRASIK, Journal of Applied Physics 103, 043302 (2008) 043302-1 - 043302-11

4. E. OKS, Plasma Cathode Electron Sources, Physics, Technology, Applications, WILEY-VCH Verlag GmbH \& Co. KGaA, Weinheim, Germany, (2006)

5. E. OKS, Plasma Cathode Electron Sources, BATAN Accelerator School, Yogyakarta, December $5^{\text {th }}$ 9 $^{\text {th }}$, (2011)

6. Y. BING, W. YUTIAN, L. HUI, W. HUIXIN, C. YIQIANG, Sensors \& Transducers, Vol. 165, Issue 2, February (2014) 35 - 39

7. G. CROTTI, D. GIORDANO, A. MORANDO, XIX IMEKO World Congress Fundamental and Applied Metrology, Lisbon, Portugal, September 6-11, (2009) 876 - 881

8. B. DJOKIC, IEEE Transactions on Instrumentation and Measurement, Vol. 59, No. 5, May (2010) 1303 - 1308

9. A.S. TODOROVIC and M.D. JEVTIC, Facta Universitatis, Ser.: Elec. Energ., Vol. 23, No. 2, August (2010) $199-206$

10. Y. WANG, J. LI, Y. HU, R. AN, Z. CAI, R. HE, Energy and Power Engineering,5, (2013) 1324-1329

11. M. REZAEE and H. HEYDARI, Iranian Journal of Electrical \& Electronic Engineering, Vol. 6, No. 4, December (2010) 232 - 237

12. G.M. HASHMI and M. LEHTONEN, International Journal Innovations in Energy Systems and Power, Vol. 4, No. 2, October (2009) 14 - 34

13. A. PURWADI, Jurnal Iptek Nuklir Ganendra, Vol. 17, No. 2, Juli (2014) 75 - 82 